\title{
The Surprising Incidence of Tax Credits for the Toyota Prius
}

\author{
(Supplementary Materials) \\ James M. Sallee \\ University of Chicago
}

\section{A Dealer Cost versus Prices}

This appendix provides details about the measure of dealer cost used throughout the paper, analyzes the stability of this measure and documents the adjustment made to account for the price change instituted by Toyota in April 2007. The results presented in the paper above are sensitive to whether or not dealer cost is controlled. Thus, it is important to determine whether or not dealer cost varies over time because Toyota charges dealers a different amount for identical cars, or because the percentage of cars with more expensive options fluctuates. Toyota also made a change to invoice and sticker prices in April 2007, which it called an "economic savings bonus." The base price of the vehicle did not change, but the invoice and sticker price of each options package did. Thus, to compare identical vehicles before and after the tax change, it is necessary to adjust dealer cost for cars sold in April, which requires knowing which options package each vehicle had. Since their is no indicator for options packages in the data, I develop a method for assigning options packages to each car by examining the dealer cost data.

In the case of the Prius, the vast majority of the variation in dealer cost comes from the factory-installed options package. The 2006 Prius had eight options packages, and the 2007 Prius had six. Each vehicle is shipped from the factory with one of these options packages installed, adding up to $\$ 6,000$ to dealer cost. If the data included an indicator for each options package, one could simply see if Priuses with any particular options package cost the same amount before and after each tax change. Even without this, if the dealer cost variable in the data was influenced only by the options package, then the dealer cost measure 
could easily be matched to outside information on the invoice price of each package. There are other factors that influence the dealer cost, however, which introduce noise into this procedure.

Dealer invoice of the base model and each options package is readily available from online sources, which acquire this information and provide it to consumers for purposes of price negotiation. The challenge is to match this precisely to the measure of dealer cost in the data. The measure of dealer cost available in the data includes factory installed options, dealer installed "hard add" options, advertising fees and the delivery charge. It does not include what is known as the holdback.

Factory-installed options include not only the options package, but also small additional features, like floor mats, a cargo net or a satellite radio. Thus, two Priuses with the same options package may differ in price because one includes a cargo net, and the other does not. Dealer cost will also reflect "hard adds," features that add to the resale value of the car, such as a roof rack or upgraded tires. It is impossible to determine from cost data alone which of these features is present in a vehicle, and these factors therefore introduce noise into the process.

Dealer invoice prices for identical items typically do not vary across localities, in accordance with franchise law, but geographic variation does arise in small measure through fees. Toyota adds $\$ 55$ to the delivery fee for Alabama, Georgia, Florida, North Carolina and South Carolina. Since the delivery charge is a known function of state, I can easily account for this in the calculations. There may also be some geographic variation in document preparation fees, however, which will introduce a small amount of noise. More substantial variation may come through advertising fees, which are typically between $1 \%$ and $3 \%$ of the base MSRP for a vehicle, depending on the cost of advertising in the local market. There is no reliable source of information that indicates the variation across geography in advertising fees. My accumulation of anecdotal evidence, however, suggests that most Priuses were charged very close to $2 \%$ of base MSRP. 
The final important discrepancy between dealer invoice and dealer cost is what is known as the holdback. The holdback is a rebate that the dealer receives from the manufacturer after a car is sold. In the case of Toyota, the dealer holdback is known to be $2 \%$ of the base MSRP. Thus, dealer invoice prices quoted in consumer resource guides are $2 \%$ higher than the actual final cost to the dealer. Since the measure of cost in the data nets out holdback, it is necessary to subtract holdback from the invoice price to make them comparable. Since the cost measure includes advertising fees, however, which are estimated to also be roughly $2 \%$ of base MSRP, I let these two omissions cancel each other out. This will be correct on average, but it will induce variation, to the extent that advertising fees are above or below $2 \%$ in a particular location.

Thus, several considerations create small amounts of variation in the dealer cost measure. This variation makes it impossible to match exactly each vehicle to an appropriate invoice price and thereby infer the options package. Fortunately, the noise appears to be small enough that the imputation is meaningful. In figure 9, I show a kernel smoothed density of the dealer cost of all 2007 Priuses in the sample between September 2006 and March 2007. The dealer cost variable is adjusted for the $\$ 55$ surcharge on deliveries in the relevant states. The vertical bars are at invoice prices, estimated from Edmunds.com data as follows: I sum the base price, options package price and delivery fee for each vehicle. Based on my reading of numerous consumer accounts, I add the dealer invoice price of floor mats to all but the least expensive options package, since all consumers report floor mats being included on all Priuses with options package 2 or greater in these years. Overall, figure 9 shows remarkable consistency between high points in the density, and the invoice prices. If advertising fees are on average $2 \%$ (and thereby offsetting the holdback on average), we would expect modal prices to be somewhat to the right of each line, since small additional options would add weight to the distribution asymmetrically.

Now, I move specifically to a discussion of how cost may vary around each tax change. The dealer's invoice price for a vehicle rarely changes during the model year cycle. When 
these prices do change, this is usually a part of a public campaign, as in the case of the "economic savings bonus" for the Prius in April 2007. Instead, the manufacturer typically manipulates price by offering cash incentives to dealers. Automotive News reports on these types of incentives for all models weekly, and it reports no such dealer cash incentives for the Prius until April 2007, at which point a very small incentive may have been in place (see footnote 8 for details and citations). Thus, we are looking for confirmation that there were no other cost changes.

Figures 10 to 12 show kernel density plots of vehicle cost for the two months surrounding each tax change. Looking at the first two tax changes, it is apparent that there was a composition shift. There were clearly more richly equipped Priuses sold in December 2005 than January 2006; and there were clearly fewer sparsely equipped Priuses sold in September 2006 than October 2006. In addition, there appear to be spikes in prices that line up at nearly identical values in each case. This suggests that, for these two experiments, there was a noticeable composition change, but that identically optioned cars cost dealers the same amount before and after the tax changes. Note that, if one thought that Toyota captured the subsidy by increasing the share of high profit margin vehicles in the high subsidy time period, then one would expect to see similar composition changes around each tax change. In contrast, it appears that more fully equipped vehicles were sold in January 2006 (high subsidy) and in October 2006 (low subsidy), indicating that the composition changes operated in opposite directions.

As expected, figure 12 tells a different story. In this case, there appears to be both a shift in composition and a dramatic shift downward in cost from March to April 2007. This coincides with the introduction of Toyota's sale. Since the composition does not appear stable, it is important to compare cost adjusted consumer prices to estimate a tax effect. To do so, I assign an options package value to each vehicle from April 2007 and then use the cost measure that would have been in effect for that vehicle, had it been sold in March. Note that this procedure will blur dealer's gross profit and confuse the allocation of benefits between 
Toyota and dealers, but, if the assignment is correct, it will accurately reflect consumer prices.

Table 9 shows the MSRP and dealer invoice prices for each options package before and after the price change, according to Edmunds.com. I assign each Prius an options package as follows. I add the base price, the delivery charge $(\$ 660)$, and the cost of floor mats $(\$ 141)$ to each options package according to April prices. Because locations with lower than average advertising fees will have costs below this number, I assign cut-off values at $\$ 100$ below this number. Any Prius with a price greater than this number, but less than the next highest cut-off is assigned to that options package. Having assigned options packages, I then add the cost difference back into dealer cost. If the vehicles were correctly assigned, then the dealer cost will now be identical to the dealer cost in March for the same vehicle.

Figure 13 shows the adjusted April cost distribution against the March distribution. These now look remarkably similar in the location of peaks. This highlights again that there was a composition change, with more expensive options packages being sold in April. Overall, this similarity of the March and April distributions suggests that the adjustment procedure did a good job assigning options values based on cost.

Figures 10 to 13 provide visual evidence to support the industry reports that suggest costs were stable through the tax windows, once one has accounted for the April price cut. A statistical test of this proposition can be performed as follows. First, I use the same procedure as described above to assign options packages to each vehicle based on cost to assign all 2006 and 2007 Priuses an options package. Then, I run a regression of the form:

$$
\text { Cost }_{i j}=\alpha H+\psi_{j}+\varepsilon_{i j}
$$

separately for each four week period surrounding a tax change, where $H$ is a dummy for the high tax portion of that window and $\psi$ are options package fixed effects. The regressions exclude a small number of vehicles that lie below the estimated minimum invoice price 
and vehicles more than $\$ 1,000$ above the maximum. Table 10 reports the coefficients and standard errors on $\alpha$. Sensitivity analysis showed that some results are sensitive to the size of the downward adjustment for minimum prices in a tier. I thus report a variety of values.

Overall, this table confirms the industry reports and visual evidence. Dealer cost did not change within the tax windows, except for the known sale in April. Column 1 shows that, in only 1 of 6 cases is the difference in January and December costs statistically significant. In no case is the September to October difference significant. In the March versus adjusted April comparison (column 3), 3 of 6 cases yield a significant difference. This may be due to imperfections in the cost adjustment, or it may be a statistical anomaly. As expected, if this procedure is used to compare the March and the unadjusted April numbers, there is a vast difference in costs.

\section{B Robustness of Main Estimates and Additional Re- sults}

\section{Calculation of Financing Incentives}

The Federal Reserve's benchmark interest rate is a market wide average. It may not be an excellent counterfactual for any given individual, but it should be accurate for the average car buyer. If Prius buyers, however, are different on average than other car buyers in terms of credit, then this market average will be a biased estimate for the average Prius buyer. To account for this possibility, I calculate the difference between the average APR of all Prius buyers and the market rate, during the wait list time period, at which time one expects that Toyota was not subsidizing loans. For the 2004, 2005 and 2006 model years, Prius buyers received an average APR that was one-half point below the market rate, suggesting that they have better credit than the average new car buyer. I construct a modified counterfactual market interest rate by subtracting this premium from the Federal Reserve's survey rate.

One other approach is suggested by Corrado et al. (2006). They use data from the Survey 
of Consumer Finances to estimate the determinants of the interest rate obtained on new car loans. They report that each year of age is associated with a .05 point reduction in the interest rate, and use this to adjust the counterfactual interest rate so that a person at the mean age receives the unadjusted rate, and those above or below receive a modified rate. I construct a modified counterfactual market interest rate by following their procedure. ${ }^{35}$

Table 11 reports a series of bounding estimates that use the original measure of financing incentives, the measure that adjusts for the Prius premium and the age adjusted measure, and also varies the discount rate. The table reports bounding estimates from a specification with control variables, which matches columns five and six in the top panel of table 3 . The estimates in bold face are identical to those estimates.

As expected, the bounds on the first and second tax change are affected very little by the discount rate or the interest rate measure used. The upper bound does rise somewhat when the age adjusted measure is used. This is not surprising, since the upper bound will rise whenever variance increases, and the adjustment procedure will increase variation by modifying significantly the counterfactual interest rate at very high or low ages. As was suggested by the difference between results using a $4 \%$ discount rate and those using a $7.23 \%$ discount rate in table 3 , the statistically significant negative sign of the lower bound on the third tax change is eliminated at higher discount rates, but it is affected relatively little by the choice of interest rate measure. Thus, it is possible that the significant, negative sign is the result of the choice of discount rate. The high upper bound, however, is qualitatively unaffected.

\section{Time Period Effects}

The estimates above are based on prices observed in different time periods. By using a narrow window around each tax change, the estimator mitigates the probability that macroeconomic shocks caused Prius price movements. The tax changes, however, are each on the first day

\footnotetext{
${ }^{35}$ I assign observations with missing age the unadjusted Federal Reserve interest rate.
} 
of a new quarter. Automobile manufacturers are sometimes willing to cut prices at the end of a quarter in order to meet sales targets, so it is worth investigating whether or not other models showed significant prices changes around these dates.

Table 12 replicates the before-after comparison of column 5 from table 3 using several samples of non-hybrid vehicles, in order to estimate whether or not there were unusual price movements in the car market as a whole. The samples include non-hybrid Toyota sedans (6 models), the set of best-selling sedans in the same vehicle class from each nameplate (28 models, including all 6 Toyotas), and a subset who have an EPA rated combined fuel economy above 29 miles per gallon ( 8 models). The coefficients are not scaled by tax changes, so they are interpreted as dollar changes around the tax date. For example, the first column says that, on average, among all non-hybrid Toyota sedans, prices fell by $\$ 50$ from late December 2005 to early January 2006.

Overall, table 12 gives little reason to believe that time effects significantly influence the tax estimates for the Prius. Only three of nine coefficients are statistically significantly different from zero, and all are small in magnitude. Adjusting the tax estimates for the Prius according to even the largest of these estimates would have an insignificant impact on the main conclusions of this paper.

Another way to look for time period effects is to look at each model individually. Table 13 shows the estimated time period effects from the same specification for every vehicle manufactured by Toyota, including vehicles sold under the Lexus and Scion brands. Several of the Lexus models sell for more than twice the amount of the Prius. Given this variance across models, table 13 uses estimates on log price to make coefficients more comparable. Statistically significant time effect estimates are labeled with an asterisk. There is no overall pattern in table 12 that would suggest a caution for the Prius estimates. While there are some statistically significant, small price movements, there is little action among sedans, and many of the price movements in any given window are of opposing sign.

In sum, the principal conclusions of the bounding estimates in table 3 are robust to 
concerns regarding the use of a single model year, assumptions made in the construction of financing incentives, and time period effects in the broader new vehicle market. The only potentially important deviation from the baseline estimates is that the alternative methodology for estimating the number of stayers present in the high tax window does raise the upper bound on the estimate for the second tax change.

\section{Inclusion of Additional Model Years}

The regressions reported in table 3 estimate the incidence of the tax using selected model year and trim combinations in order to prevent shifts in the model year composition from biases results. Table 14 relaxes that assumption in several ways to demonstrate that the main conclusions of the paper are robust to this modeling choice. Column 1 simply restates the main estimates from the paper (table 3 column 5). Column 2 repeats this specification, but it drops observations that are not in the main model years used for estimation if the observation occurs in the treatment windows. For example, the December 2005 to January 2006 tax response is identified from the 2006 model year, but there are 2005 model year vehicles sold in that time period. In column 2, the 2005 observations that take place within two weeks of January 1, 2006 are excluded from the regression. This has almost no effect on the estimates because the main specification estimates both the treatment and the control averages using only the main vintages.

An alternative is to include all of the model years and trims. Column 3 does this by simply turning on the treatment and control dummies for all vehicles sold in the four week windows, regardless of model year and trim. Because there are model and trim dummy variables included in the regression, this would be a reasonable specification if the composition of model year and trim did not change substantially within the event windows. As shown in table 2, there is a shift from the 2006 towards the 2007 model year surrounding the second tax change, but no large shift coincides with the other two events. As a result, this specification provides very similar results for the first and third tax event, but the estimate becomes 
noticeably more negative for the second event. This result, taken at face value, would only enhance the main assertion of the paper that prices did not rise with more generous tax credits.

A better approach for including the supplementary models and trims is shown in column 4, which includes a separate treatment and control dummy variable for each model year and trim at each tax event. All of the coefficients in column 4 come from a single regression. The highlighted values are the estimates that correspond to the model years used in the baseline estimates from column 1 . These coefficients are very similar, suggesting that including the other treatment estimates has little impact on the main results. These other incidence parameters have much larger standard errors because there are far fewer observations (the extreme case being model year 2006, which has 2 observations on other side of the tax window for event three - table 2 includes all of the relevant sample sizes). The one exception is the 2005 model year estimates around the first tax event, which are fairly well estimated but are, again, surprisingly negative.

In sum, including the other model years and trims in the estimation has very little effect on the main estimates, and where it does have a noticeable impact it pushes the results even further in support of the paper's main argument that prices did not rise in response to more generous tax credits.

\section{Model Year and Trim Coefficients}

Table 15 reports the model year and trim level dummy variable coefficients from table 3 . These estimates are perfectly consistent with expectations. The omitted category is the 2007 Touring edition, which is the most expensive model. Consequently, all coefficients are negative in column 1, and earlier model years have larger coefficients. Once vehicle cost is controlled, the pattern changes as expected, so that the large positive numbers for model years 2004 - 2006 indicate that these vehicles sold for higher profit, which is consistent with their being sold during the wait list period. 


\section{Evidence from Other Hybrid Vehicles}

Evidence from other hybrid models broadly confirm that vehicles that had tight supply look similar to the Prius in their response to taxation. ${ }^{36}$ The Toyota Camry, Toyota Highlander, Honda Civic and Ford Escape all have a sufficient sample size to replicate the main Prius estimates. Neither the Escape nor the Highlander ever had an especially fast turnover in the sample, but both the Camry and the Civic had turnover similar to the Prius around the policy changes, indicating that supply was extremely tight. Table 16 reports the incidence bounds for these other vehicles using the same specification as column three in table 3 , and results from a state panel regression of the same form as table 7 . Though imprecise in places, these estimates line up with the predictions of the wait list story. The Civic and Camry look very similar to the Prius, while the Escape and Highlander appear more responsive to tax changes. Note that the bigger state price effects for the Escape and Highlander appear in the specification without cost controls, which may be preferred because these vehicles did experience dealer incentives throughout the sample.

\section{A Heuristic Two-Period Model of Vehicle Demand}

This appendix develops a heuristic two period model of the demand for vehicles that illustrates how the link between past prices and current demand might influence tax incidence. I develop a simple two period example in which a monopolistic seller faces a first period capacity constraint and first period price is assumed to influence second period demand. I show that a first period tax credit may have no influence on the price.

For ease of exposition, I assume linear demand and posit a multiplicative relationship between first period prices and second period demand. This provides closed-form optimal values and transparent comparative statics. Let $D$ denote demand, $p$ price, $\tau$ the tax subsidy,

\footnotetext{
${ }^{36}$ Another approach would be to test for a difference in the state panel regression between the wait list period and the non-wait list period. Unfortunately, there is no variation in state policies during the non-wait list portions of the sample period, so this is not possible.
} 
and denote second period variables with a prime ( $)$. Then

$$
\begin{aligned}
& D=\alpha(A-(p-\tau)) \\
& D^{\prime}=\left(\alpha^{\prime}-.5 \beta(p-\kappa \tau)^{2}\right)\left(A^{\prime}-\left(p^{\prime}-\tau^{\prime}\right)\right)
\end{aligned}
$$

where $A, A^{\prime}, \alpha$, and $\alpha^{\prime}$ are positive scalars that shift the size of the market in each period. $\beta$ is a scalar that describes how first period price influences second period demand, and $\kappa$ determines whether the tax inclusive or the tax exclusive price shifts demand. If $\beta$ is zero, then the model collapses to a standard case. If $\beta$ is positive, then high first period prices shrink future demand. If $\kappa=1$ then the tax inclusive first period price shifts demand, but if $\kappa=0$ then consumers ignore the first period subsidy when determining demand and respond to the tax exclusive price. The setup assumes that consumers remit the tax. As a regularity condition, assume that $\alpha^{\prime}-.5 \beta(p-\kappa \tau)^{2}>0$ for the optimal $p$.

The firm produces $Q$ units at constant marginal cost $c$ in both periods, but it faces a capacity constraint in the first period, at which time it can produce only up to $N$ units. ${ }^{37}$ Thus, it maximizes profits $(\pi)$ by solving the following problem:

$$
\begin{gathered}
\max _{p, p^{\prime}} \pi=(p-c) Q+\left(p^{\prime}-c\right)\left(\alpha^{\prime}-.5 \beta(p-\kappa \tau)^{2}\right)\left(A^{\prime}-\left(p^{\prime}-\tau^{\prime}\right)\right) \\
\text { where } \quad Q=\left\{\begin{array}{rll}
\alpha(A-(p-\tau)) & \text { if } & \alpha(A-(p-\tau)) \leq N \\
N & \text { if } & \alpha(A-(p-\tau))>N .
\end{array}\right.
\end{gathered}
$$

Simple first order conditions provide optimal prices. Of interest here is the constrained case, when $Q=N<\alpha(A-(p-\tau))$. The optimal prices, denoted $*$ for optimal and $N$ for

\footnotetext{
${ }^{37}$ The capacity constraint is exogenous in this example. It can be thought of as arising from a choice made in a prior period, in which the producer must pay fixed costs to build capacity but is uncertain of demand.
} 
the constrained quantity are:

$$
\begin{aligned}
p_{N}^{*} & =\frac{N}{\beta\left(\frac{A^{\prime}+\tau^{\prime}-c}{2}\right)^{2}}+\kappa \tau \\
p_{N}^{*} & =\frac{A^{\prime}+\tau^{\prime}+c}{2} .
\end{aligned}
$$

In this setup, the multiplicative effect of first period price on second period demand means that the optimal second period price is independent of first period parameters. So, the second period price shows nothing unusual. The first period price, however, is a function of the second period demand parameters, as opposed to first period parameters. The parameters of the first period demand curve are no longer relevant because the seller has chosen a price - quantity bundle that is not on the demand curve; the firm is losing first period profit (and creating rationing) in exchange for increased profit in the second period.

The comparative statics can be seen by inspection from the optimal price. To match the data, we are looking for a case where $\frac{\partial p_{N}^{*}}{\partial \tau}=0$. This is only possible if the seller is constrained, $\beta>0$ and $\kappa=0$. If $\beta=0$ then we cannot be in the constrained case; the seller would always raise prices in the first period until demand fell to $N$. If $\kappa=1$, and consumers respond to the tax inclusive price, then $\frac{\partial p_{N}^{*}}{\partial \tau}=1$. This indicates a set of conditions under which a temporary tax credit for the Prius might not influence the current price. This would be true if (a) Toyota was capacity constrained when the subsidy was available, (b) by raising price while the tax credit was available, Toyota would hurt the market for their product in the future, and (c) consumers responded to tax exclusive prices.

If the pretax price influences future demand, statutory incidence will influence economic incidence. Had the government given Toyota a production credit instead of crediting consumers, we might thus expect Toyota to have enjoyed the gains instead of consumers. This has intuitive appeal: would we have expected Toyota to lower prices by $\$ 2,750$, while already rationing sales, because the government upped a production subsidy? The plausibility of this interpretation is discussed at length in the main text. 
Figure 9: Estimated Density of Dealer Cost for Prius, September 2006 to March 2007

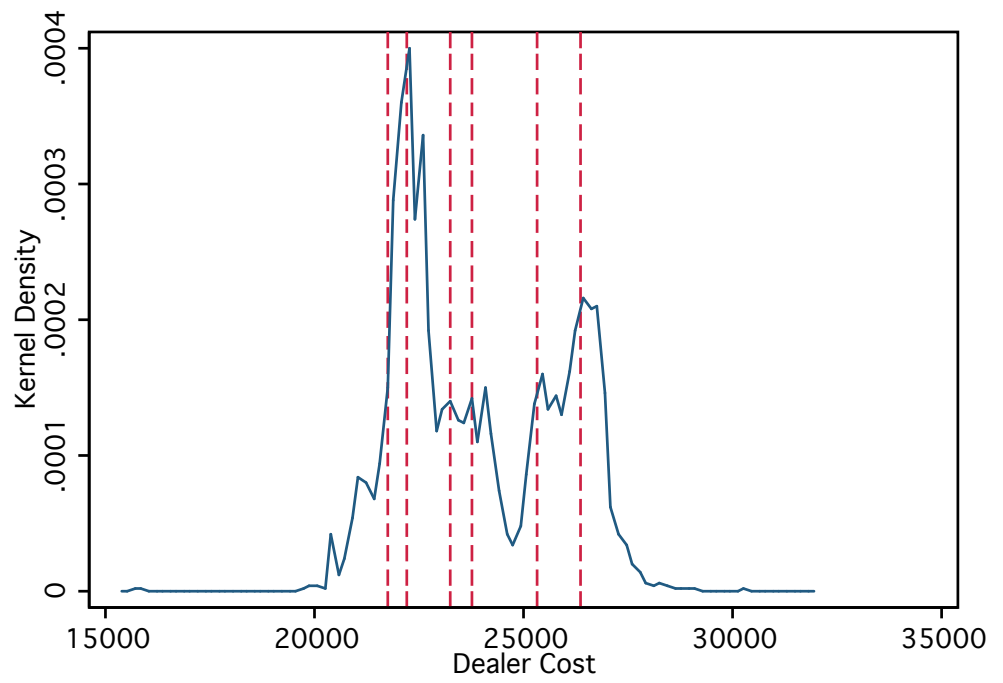

Vertical bars indicate estimated minimum invoice prices for each options package.

FIGURE 10: Estimated Density of Dealer Cost for Prius, December 2005 and January 2006

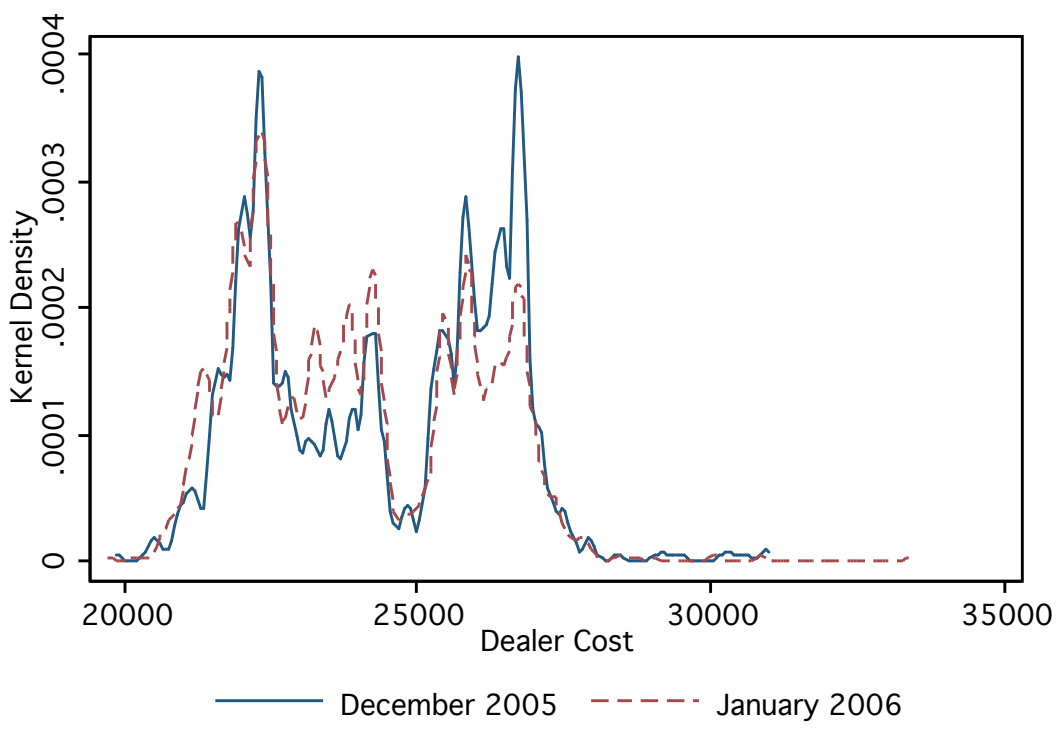


FIGURE 11: Estimated Density of Dealer Cost for Prius, September and October 2006

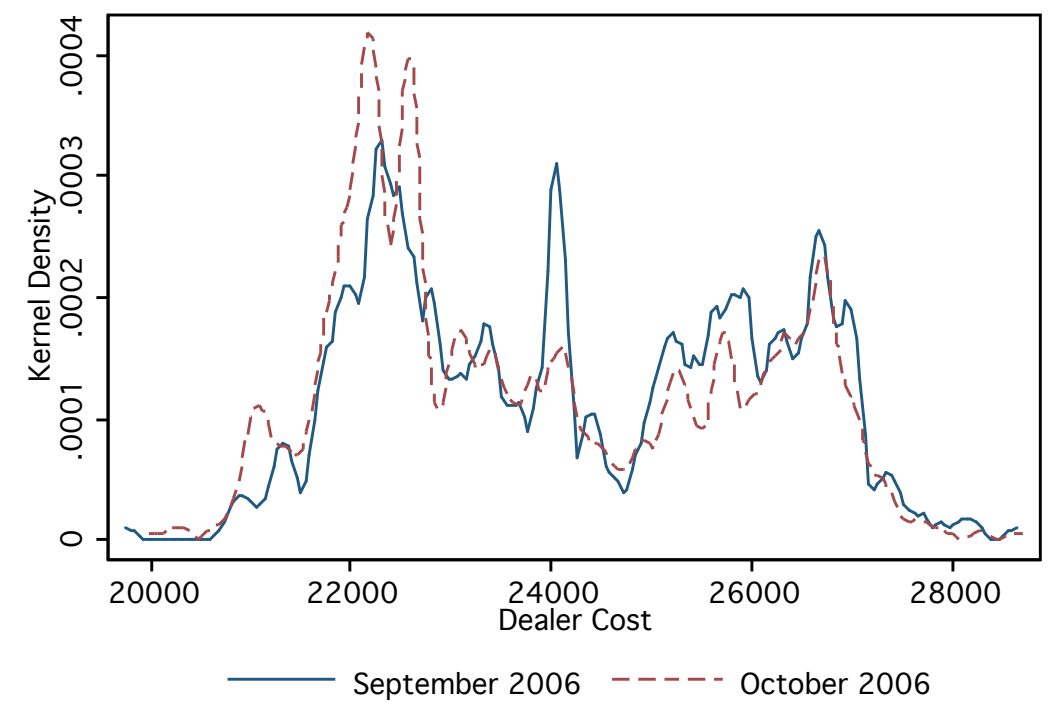

FIGURE 12: Estimated Density of Dealer Cost for Prius, March and Original April 2007

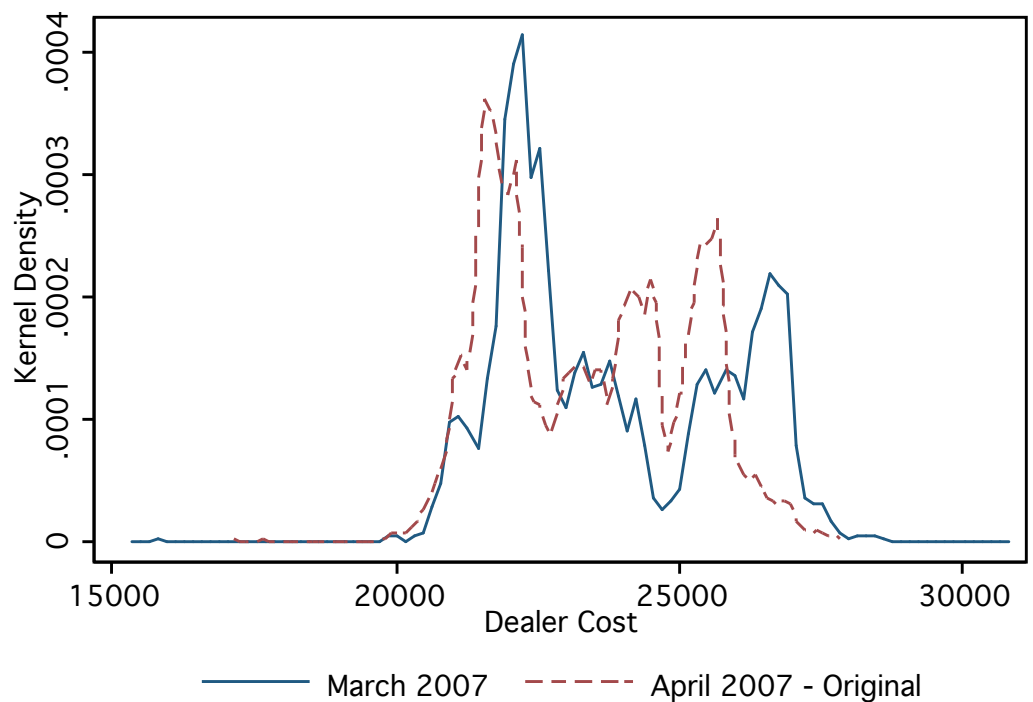


FIGURE 13: Estimated Density of Dealer Cost for Prius, March and Adjusted April 2007

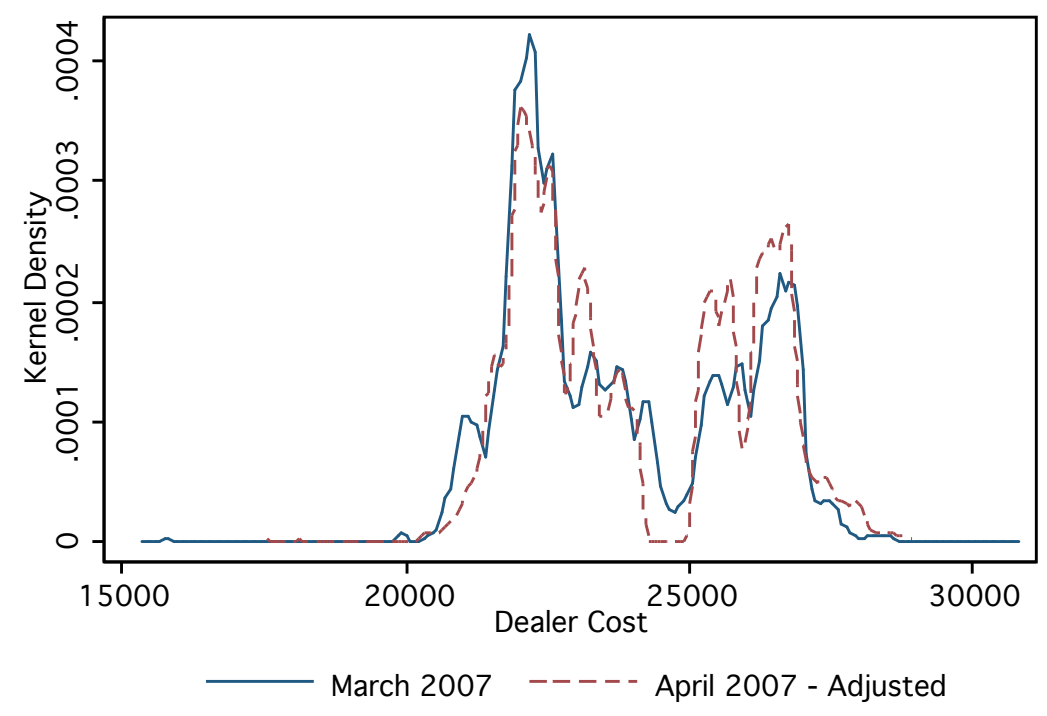


TABle 9: Price Changes Due to "Economic Savings Bonus" for 2007 Prius

\begin{tabular}{|c|c|c|c|c|}
\hline \multicolumn{5}{|c|}{$\begin{array}{l}\text { Manufacturer's } \\
\text { Suggested Retail Price }\end{array}$} \\
\hline Base & & $\$ 22,175$ & 22,175 & 0 \\
\hline \multirow{6}{*}{ Package } & 1 & 825 & 825 & 0 \\
\hline & 2 & 1,175 & 575 & 600 \\
\hline & 3 & 2,555 & 2,105 & 450 \\
\hline & 4 & 3,180 & 2,580 & 600 \\
\hline & 5 & 5,080 & 3,280 & 1,800 \\
\hline & 6 & 6,350 & 4,550 & 1,800 \\
\hline
\end{tabular}

\section{Dealer Invoice}

\begin{tabular}{|c|c|c|c|c|}
\hline Base & & 20,419 & 20,419 & 0 \\
\hline \multirow[t]{6}{*}{ Package } & 1 & 659 & 659 & 0 \\
\hline & 2 & 960 & 518 & 442 \\
\hline & 3 & 2,018 & 1,895 & 123 \\
\hline & 4 & 2,518 & 2,322 & 196 \\
\hline & 5 & 4,133 & 2,952 & 1,181 \\
\hline & 6 & 5,149 & 4,095 & 1,054 \\
\hline
\end{tabular}

Source: Edmunds.com

TABLE 10: Dealer Cost Premium in High Tax Period, Within Assigned Options Package 2007 Prius

\begin{tabular}{|c|c|c|c|c|}
\hline Options Package Threshold & Jan 06 (v. Dec 05) & Sep 06 (v. Oct 06) & $\begin{array}{c}\text { Adjusted } \\
\text { Mar } 07 \text { (v. Apr 07) }\end{array}$ & $\begin{array}{c}\text { Unadjusted } \\
\text { Mar } 07 \text { (v. Apr 07) }\end{array}$ \\
\hline$\$ 25$ & $\begin{array}{c}-8.47 \\
(18.60)\end{array}$ & $\begin{array}{l}-13.84 \\
(22.30)\end{array}$ & $\begin{array}{c}-39.34 \\
(14.10)\end{array}$ & $\begin{array}{c}619.2 \\
(15.40)\end{array}$ \\
\hline 50 & $\begin{array}{l}-17.16 \\
(18.40)\end{array}$ & $\begin{array}{c}-12 \\
(22.00)\end{array}$ & $\begin{array}{c}-31.37 \\
(14.00)\end{array}$ & $\begin{array}{c}625.2 \\
(15.40)\end{array}$ \\
\hline 75 & $\begin{array}{l}-16.98 \\
(18.30)\end{array}$ & $\begin{array}{l}-12.31 \\
(22.10)\end{array}$ & $\begin{array}{l}-30.38 \\
(13.70)\end{array}$ & $\begin{array}{c}624.7 \\
(15.30)\end{array}$ \\
\hline 100 & $\begin{array}{l}-42.62 \\
(18.00)\end{array}$ & $\begin{array}{l}-13.94 \\
(22.10)\end{array}$ & $\begin{array}{l}-26.47 \\
(13.60)\end{array}$ & $\begin{array}{c}629.9 \\
(15.30)\end{array}$ \\
\hline 125 & $\begin{array}{l}-24.6 \\
(17.60)\end{array}$ & $\begin{array}{l}-12.45 \\
(22.10)\end{array}$ & $\begin{array}{l}-19.98 \\
(13.50)\end{array}$ & $\begin{array}{c}637.1 \\
(15.20)\end{array}$ \\
\hline 150 & $\begin{array}{l}-22.19 \\
(17.20)\end{array}$ & $\begin{array}{c}-13.1 \\
(22.10)\end{array}$ & $\begin{array}{c}-6.52 \\
(13.20)\end{array}$ & $\begin{array}{c}651.5 \\
(15.20) \\
\end{array}$ \\
\hline $\begin{array}{l}\text { Fixed Effect for Assigned } \\
\text { Options Packages }\end{array}$ & $\mathrm{x}$ & $\mathrm{X}$ & $\mathrm{x}$ & $\mathrm{X}$ \\
\hline
\end{tabular}

Dependent variable is dealer cost. The reported coefficient is a dummy for the high tax period in each window.

Heteroskedasticity robust standard errors in parentheses.

Each coefficient is from a separate regression, which assigns each vehicle in the sample an options package if it is greater than the base price plus options price minus threshold, but less than the similarly defined cutoff for the next highest options package.

$\mathrm{N}$ is approximately 1,330 for column 1,815 for column 2 and 2,370 for columns 3 and 4 . The sample varies slightly because minimum and maximum thresholds for censoring vary slightly by the selected threshold. 


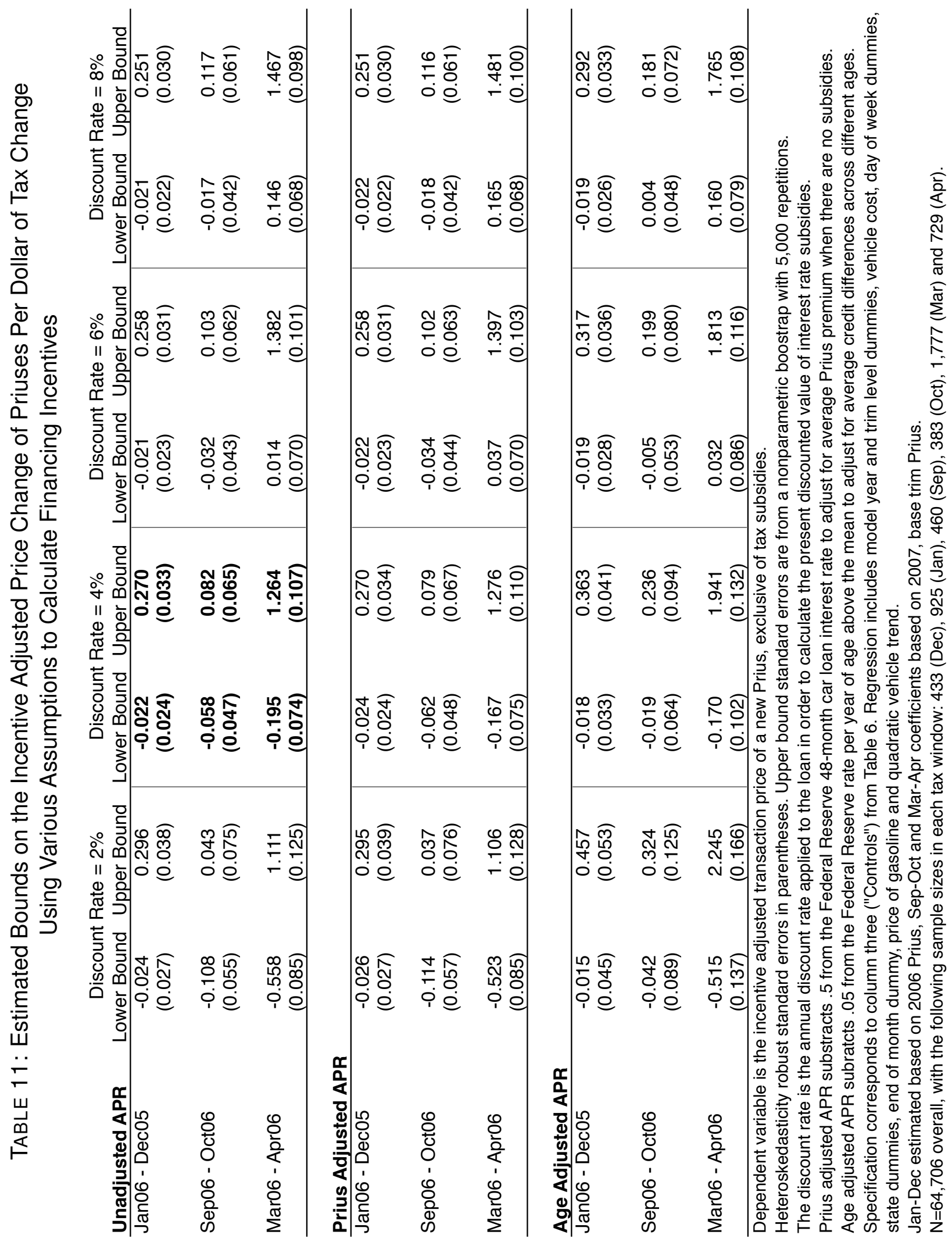


TABLE 12: Estimated Time Period Effects on Incentive Adjusted Price of Non-Hybrid Sedans in Four Week Window Surrounding Tax Change

\begin{tabular}{lccc} 
& $\begin{array}{c}\text { Comparable } \\
\text { Sedans }\end{array}$ & $\begin{array}{c}\text { Non-Hybrid Toyota } \\
\text { Sedans }\end{array}$ & $\begin{array}{c}\text { Fuel-Efficient } \\
\text { Sedans }\end{array}$ \\
\hline January 2006 - December 2005 & -49.7 & 79.3 & -69.6 \\
& $(27.0)$ & $(17.4)$ & $(24.5)$ \\
September 2006 - October 2006 & -24.4 & 25.5 & -4.5 \\
& $(22.9)$ & $(16.2)$ & $(22.8)$ \\
March 2007 - April 2007 & 49.6 & -23.6 & -12.8 \\
& $(23.2)$ & $(16.6)$ & $(22.9)$ \\
\hline
\end{tabular}

Dependent variable is the incentive adjusted transaction price of a new sedan.

Heteroskedasticity robust standard errors in parentheses.

Specification corresponds to column three ("Controls") from Table 6. Regression includes model year / trim level / engine type dummies, vehicle cost, day of week dummies, state dummies, end of month dummy, price of gasoline and quadratic vehicle trend.

Comparable vehicles are the 6, Accord, Aveo, Charger, Civic, Fit, Five Hundred, G6, Grand Prix, Impala, Impreza, LaCrosse, Malibu, Maxima, Milan, Montego, Passat, Sable, Sentra, tC, xA, xB and the non-hybrid Toyota sedans.

Non-hybrid Toyota sedans include the Avalon, Camry, Camry Solara, Corolla, Matrix and Yaris.

Fuel efficient sedans include the subset of these vehicles with a combined EPA fuel economy above 29 miles per gallon: Aveo, Civic, Corolla, Fit, Matrix, Sentra, $x A$ and $x B$.

Overall, $\mathrm{N}=1,536,075$ for comparable sedans, 570,059 for non-hybrid Toyota sedans and 584,418 for fuelefficient sedans. 


\section{TABLE 13: Estimated Log Price Premium For Toyota Models in High Tax Subsidy Window}

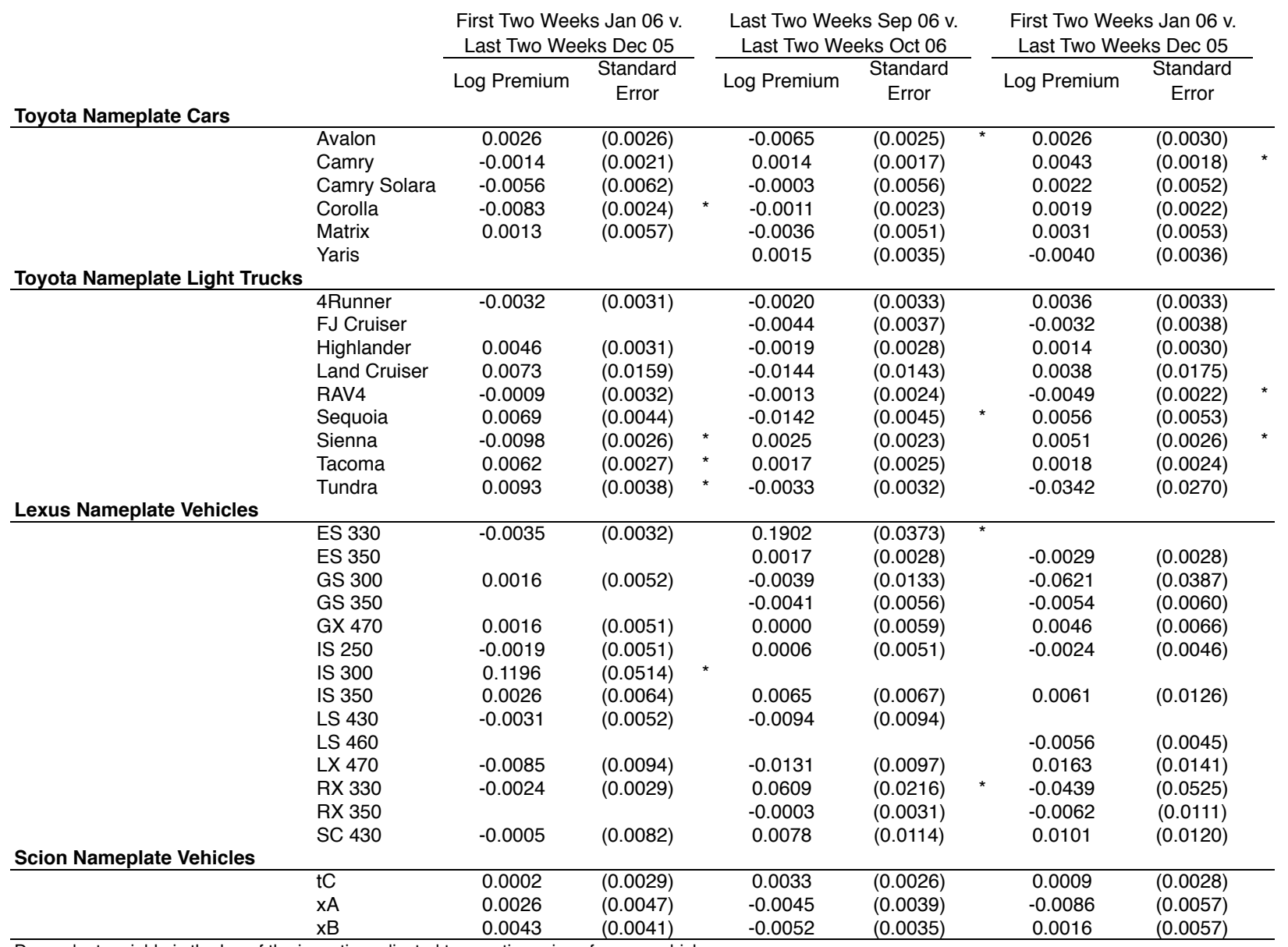

Dependent variable is the log of the incentive adjusted transaction price of a new vehicle.

Heteroskedasticity robust standard errors in parentheses. * Denotes significance at $95 \%$ level.

Specification corresponds to column three ("Controls") from Table 6. Regression includes model year / trim level / engine type dummies, vehicle cost, day of week dummies, state dummies, end of month dummy, price of gasoline and quadratic vehicle trend. 


\section{TABLE 14: Estimates of Average Price Change Per Dollar of Tax Change in Four Week Window under Various Specifications}

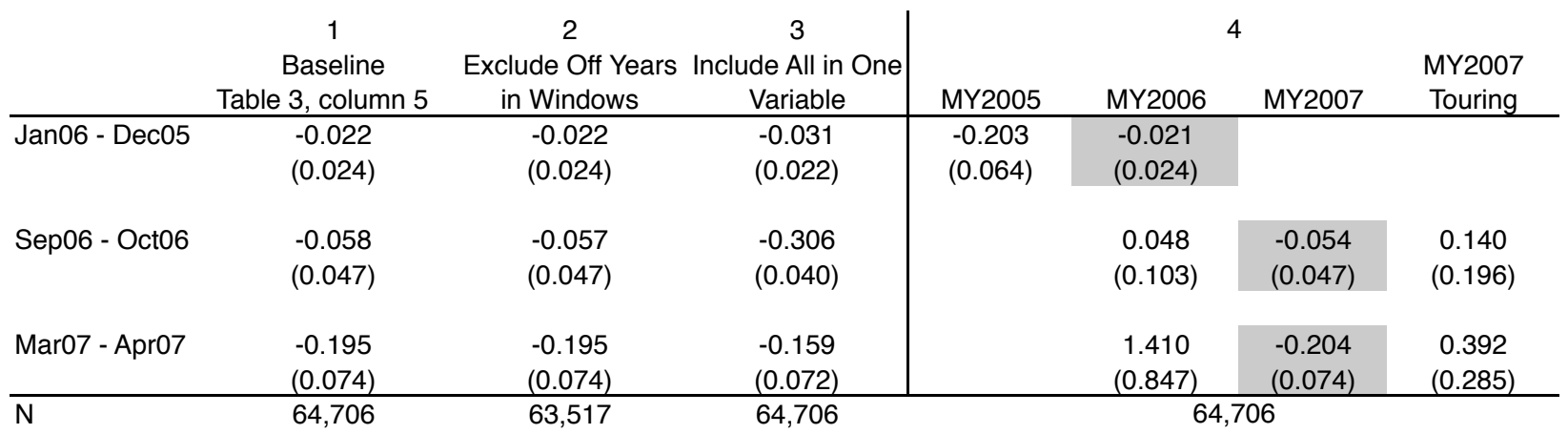

Dependent variable is the incentive adjusted transaction price of a new Prius, exclusive of tax subsidies.

Heteroskedasticity robust standard errors in parentheses.

Controls include vehicle cost, day of week dummies, state dummies, end of month dummy, price of gasoline and quadratic vehicle trend.

Column 1 matches specification in table 3 column 5 from the main paper, and uses selected model years for identification.

Column 2 uses same specification but drops observations from supplementary model years during the four week windows.

Column 3 uses same specification but includes all observations regardless of model year or trim to estimate the treatment effects.

Column 4 uses same specification but separately estimates separate treatment effects for each vehicle.

All coefficients in column 4 are from a single regression, the model years that correspond to the first three columns are shaded.

\section{TABLE 15: Model Year and Trim Level Coefficient Estimates from Table 3}

\begin{tabular}{|c|c|c|c|c|}
\hline \multicolumn{5}{|c|}{ Omitted category is 2007 Touring } \\
\hline Model Year & Column 1 & Column 3 & Column 5 & Column 7 \\
\hline \multirow[t]{2}{*}{2003} & -5594 & -407 & -340 & -308 \\
\hline & (66) & $(45)$ & $(50)$ & (49) \\
\hline \multirow[t]{2}{*}{2004} & -2225 & 1151 & 1215 & 1228 \\
\hline & $(66)$ & (42) & (46) & (44) \\
\hline \multirow[t]{2}{*}{2005} & -1552 & 1099 & 1194 & 1172 \\
\hline & (63) & $(40)$ & (41) & (39) \\
\hline \multirow[t]{2}{*}{2006} & -276 & 1111 & 1163 & 1188 \\
\hline & (63) & $(40)$ & (37) & (36) \\
\hline \multirow[t]{2}{*}{2007} & -1900 & -418 & -341 & -343 \\
\hline & (64) & $(41)$ & 38 & $(36)$ \\
\hline
\end{tabular}

Specifications match corresponding column in Table 3.

Dependent variable is the incentive adjusted transaction price of a new Prius, exclusive of tax subsidies.

Heteroskedasticity robust standard errors in parentheses. Upper bound standard errors are from a nonparametric boostrap with 5,000 repetitions. Jan-Dec estimated based on 2006 Prius, Sep-Oct and Mar-Apr coefficients based on 2007, base trim Prius.

"No Controls" includes only model year and trim level dummies.

"Composition Adjusted" adds vehicle cost as a regressor.

"Controls" adds vehicle cost, day of week dummies, state dummies, end of month dummy, price of gasoline and quadratic vehicle trend. "Extra Controls" adds sex, age, total after-market options, a dummy for an APR above the buy rate, a dummy for life insurance, a dummy for the presence of a trade-in, trade-in actual value, trade-in vintage, and a dummy for a service contract.

$\mathrm{N}=64,706$ overall, with the following sample sizes in each tax window: 433 (Dec), 925 (Jan), 460 (Sep), 383 (Oct), 1,777 (Mar) and 729 (Apr). 


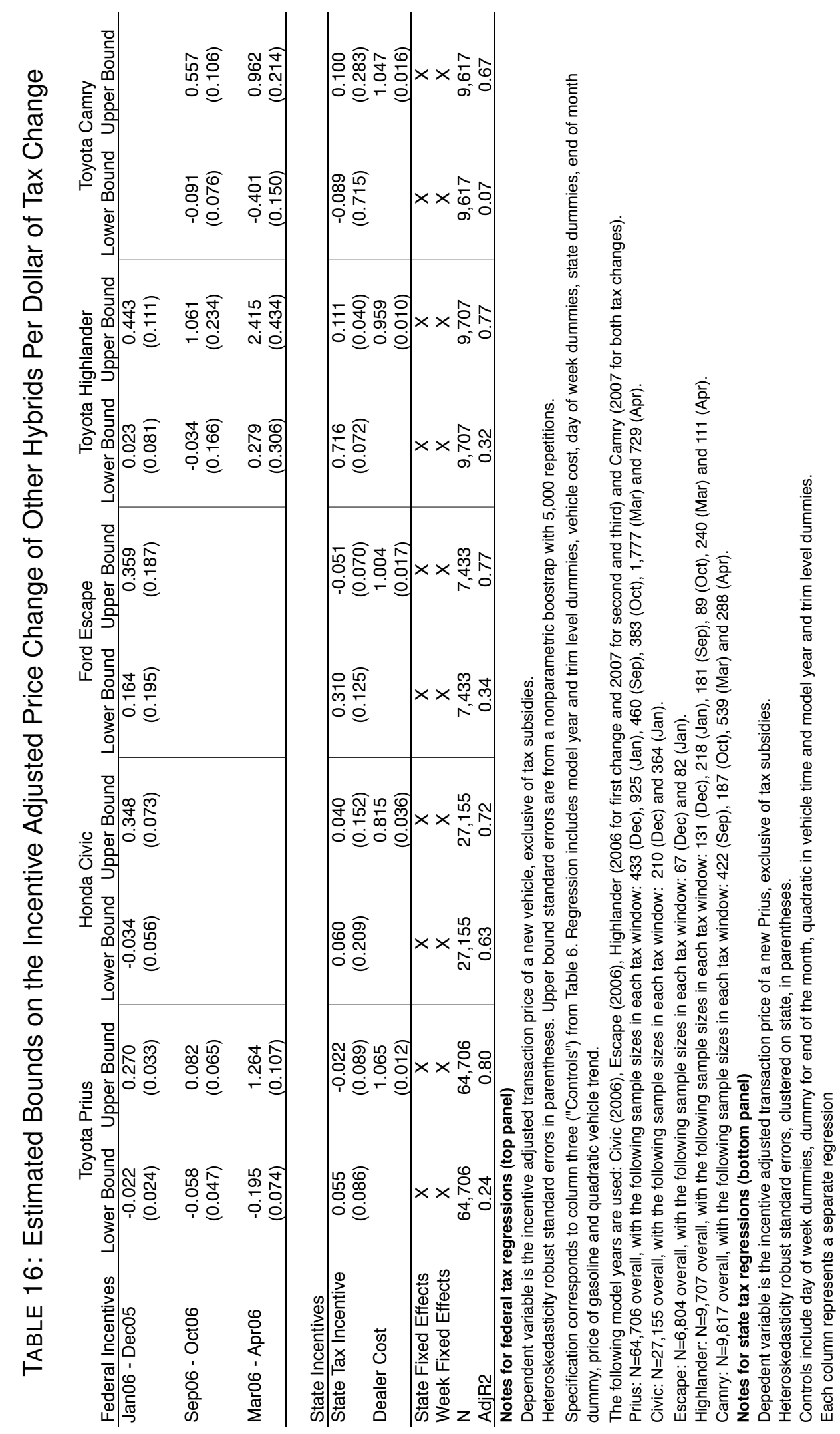

